\title{
BMJ Open MyAirCoach: the use of home- monitoring and mHealth systems to predict deterioration in asthma control and the occurrence of asthma exacerbations; study protocol of an observational study
}

\author{
Persijn J Honkoop, ${ }^{1,2}$ Andrew Simpson, ${ }^{3}$ Matteo Bonini, ${ }^{4}$ Jiska B Snoeck-Stroband,,${ }^{1,2}$ \\ Sally Meah, ${ }^{4}$ Kian Fan Chung, ${ }^{4}$ Omar S Usmani, ${ }^{4}$ Stephen Fowler, ${ }^{3}$ Jacob K Sont ${ }^{1,2}$
}

To cite: Honkoop PJ, Simpson A, Bonini M, et al. MyAirCoach: the use of homemonitoring and mHealth systems to predict deterioration in asthma control and the occurrence of asthma exacerbations; study protocol of an observational study. BMJ Open 2017:7:e013935. doi:10.1136/bmjopen-2016013935

- Prepublication history and additional material is available. To view please visit the journal (http://dx.doi.org/ 10.1136/bmjopen-2016013935).

Received 18 August 2016 Revised 14 December 2016 Accepted 30 December 2016

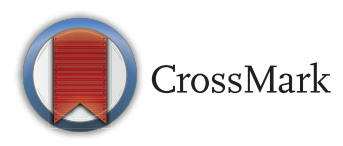

For numbered affiliations see end of article.

Correspondence to Dr Persijn J Honkoop; P.J.Honkoop@lumc.nl

\section{ABSTRACT}

Introduction: Asthma is a variable lung condition whereby patients experience periods of controlled and uncontrolled asthma symptoms. Patients who experience prolonged periods of uncontrolled asthma have a higher incidence of exacerbations and increased morbidity and mortality rates. The ability to determine and to predict levels of asthma control and the occurrence of exacerbations is crucial in asthma management. Therefore, we aimed to determine to what extent physiological, behavioural and environmental data, obtained by mobile healthcare (mHealth) and homemonitoring sensors, as well as patient characteristics, can be used to predict episodes of uncontrolled asthma and the onset of asthma exacerbations.

Methods and analysis: In an 1-year observational study, patients will be provided with mHealth and homemonitoring systems to record daily measurements for the first-month (phase I) and weekly measurements during a follow-up period of 11 months (phase II). Our study population consists of 150 patients, aged $\geq 18$ years, with a clinician's diagnosis of asthma, currently on controller medication, with uncontrolled asthma and/or minimally one exacerbation in the past 12 months. They will be enrolled over three participating centres, including Leiden, London and Manchester. Our main outcomes are the association between physiological, behavioural and environmental data and (1) the loss of asthma control and (2) the occurrence of asthma exacerbations.

Ethics: This study was approved by the Medical Ethics Committee of the Leiden University Medical Center in the Netherlands and by the NHS ethics service in the UK. Trial registration number: NCT02774772.

\section{INTRODUCTION}

Asthma is one of the most common chronic diseases worldwide, currently affecting $~ 300$ million individuals. ${ }^{1}$ According to the current

\section{Strengths and limitations of this study}

This study will assess the early detection of periods of (un)controlled asthma and the occurrence of asthma exacerbations using a wide variety of novel parameters, such as homemonitoring systems, sensors and environmental factors.

- Participants in this study are currently being treated in primary, secondary and tertiary care centres, and the inclusion and exclusion criteria are relatively limited, resulting in substantial external validity.

- In the design of this study, not only clinicians were involved, but we also included engineers from technical universities, technical and pharmaceutical companies and representatives of patients' organisations, creating a unique environment of experts, sharing different insights into problems and potential solutions.

- A limitation of this observational study is that if we manage to establish points of early detection, a future randomised controlled trial is still required to assess whether it will improve asthma outcomes if treatment is adjusted accordingly.

asthma guidelines, treatment strategies should target minimisation of symptoms, optimisation of lung function and prevention of exacerbations while minimising medication related side-effects. ${ }^{2}$ Despite wide availability of effective therapies for asthma, a considerable number of patients do not manage to achieve these proposed targets and experience a profound burden of disease,$^{34}$ with a significant impact on their quality of life and on society as a whole. ${ }^{5}$ 
There is a plethora of literature advocating the beneficial effect of self-management programmes on asthma control, ${ }^{2}{ }^{6}$ and current guidelines suggest that all participants with asthma receive education on asthma selfmanagement. ${ }^{2}$ Traditional self-management programmes involve a written plan of action of how to recognise and respond to worsening asthma. Despite significant benefits, the implementation of self-management programmes in clinical practice is low, with only one in five patients reporting that they receive a self-management programme ${ }^{7}$ and patients' adherence to self-management programmes is poor and declines over time. ${ }^{8}$

Mobile healthcare (mHealth), whether involving mobile telephone-based interactive systems or internet-based systems, includes promising tools for supporting asthma self-management. There is increasing evidence that mHealth interventions lead to an important and sustained gain in quality of life, improved clinical outcomes and support informed and educated patient autonomy. ${ }^{9-12}$ Thus far, mHealth approaches consisted of one or more of the following components: an individualised treatment plan, including self-monitoring and goal setting; medication management (including alerts and reminders); casespecific education; a digital action plan and integration with the electronic medical record of the healthcare provider. ${ }^{13}$ A recent review suggests that current applications for asthma fail to combine these aspects to a reliable supportive tool. ${ }^{14}$ This might be due to the fact that asthma is a complex condition with a heterogeneous presentation, limiting the usefulness of current mHealth systems to specific groups of patients. With the advances in technology, it is possible to imagine that the next generation of mHealth systems could be personalised to different asthma phenotypes and endotypes, making the technology beneficial to a wider group of individuals. We envisage a system that is capable of providing personalised recommendations on asthma management (ie, stepping up or stepping down treatment) based on patients' medical history and continuous/regular monitoring of their environment, physiology and behaviour.

To date, however, it is largely unknown which information would be useful in a personalised predictive model. Therefore, we aim to collect a wide range of clinical, physiological, behavioural and environmental data using current mHealth and home-monitoring systems to determine to which extent they can be used to predict asthma control and the occurrence of exacerbations. The results from this research may be used to develop tailored predictive models and personalised action points for self-management plans, which can be integrated into mHealth systems, to assist patients with the self-management of their asthma.

\section{METHODS AND ANALYSIS}

\section{Study population}

One hundred and fifty patients with a confirmed diagnosis of asthma (see box 1 for criteria) will be recruited

\section{Box 1 Inclusion and exclusion criteria}

\section{Inclusion criteria (all of the following)}

- Age 18+

- Confirmed diagnosis of asthma by either:*

- Reversibility of $12 \%$ and/or $200 \mathrm{~mL}$ in a spirometry.

- Significant peak flow variability, defined as diurnal peak expiratory flow amplitude $>8 \%$.

- Positive bronchial challenge (any type of bronchial challenge (MCh, cold air, histamine and hypertonic saline) is allowed, and cut-offs depend on the selected type).

Asthma treatment steps 2-4†, need for regular treatment with controller medication (at least 6 months in the previous year).

- Either:

- a course of oral prednisone for a minimum of 3 days, or an emergency department visit/hospitalisation for asthma, in the previous 12 months or

- current uncontrolled asthma, based on the result of the Asthma Control Questionnaire.‡

Exclusion criteria (any of the following)

- Comorbidities that cause overlapping symptoms such as breathlessness, wheeze, cough or other interfering chronic condition.§

- Unable to understand English or Dutch, as appropriate.

*Participants without a positive result to any of the above mentioned tests will have the opportunity to complete these tests in order to meet the inclusion criteria.

†According to the Global INitiative for Asthma (GINA) guidelines criteria. $^{2}$

‡Defined as an Asthma Control Questionnaire (ACQ) result $>1.5 .^{18}$ $\S$ The decision whether or not a patient should be excluded due to significant comorbidity is to be made by the treating physician.

from outpatient clinics and general practices in the regions of London and Manchester in the UK and Leiden in the Netherlands (50 patients per region). The inclusion and exclusion criteria are provided in box 1 .

\section{Study design}

This is an international, multicentre observational study that will occur alongside participant's normal asthma care, as part of the European Union Horizon 2020 funded myAirCoach project. One hundred and fifty patients with a doctor's diagnosis of asthma will be recruited from outpatient clinics and from general practices in the region of London and Manchester in the UK and Leiden in the Netherlands (50 patients per region). Patients will be informed by their pulmonologist, general practitioner (GP) or practice nurse about the study. A member of the study group will be available for additional information.

Participants will be asked to attend their GP and hospital appointments as usual, and continue to take their medication as recommended by their usual healthcare team. In addition to their usual care, participants will attend an introduction visit and complete a 12-month observational study with two phases (figure 1): 
Figure 1 Schematic of study design. At the baseline visit, all study procedures are explained. In the first month (phase I), participants are monitored daily. Phase II consists of 11 months of weekly monitoring. Additionally, in phase II, blocks of patients will be randomised over months 2-9 for a second series of 2 weeks of phase I daily monitoring. Since participants will be included and start the study over a 4-month period, all months will be covered, which allows the assessment of the influence of seasonality.

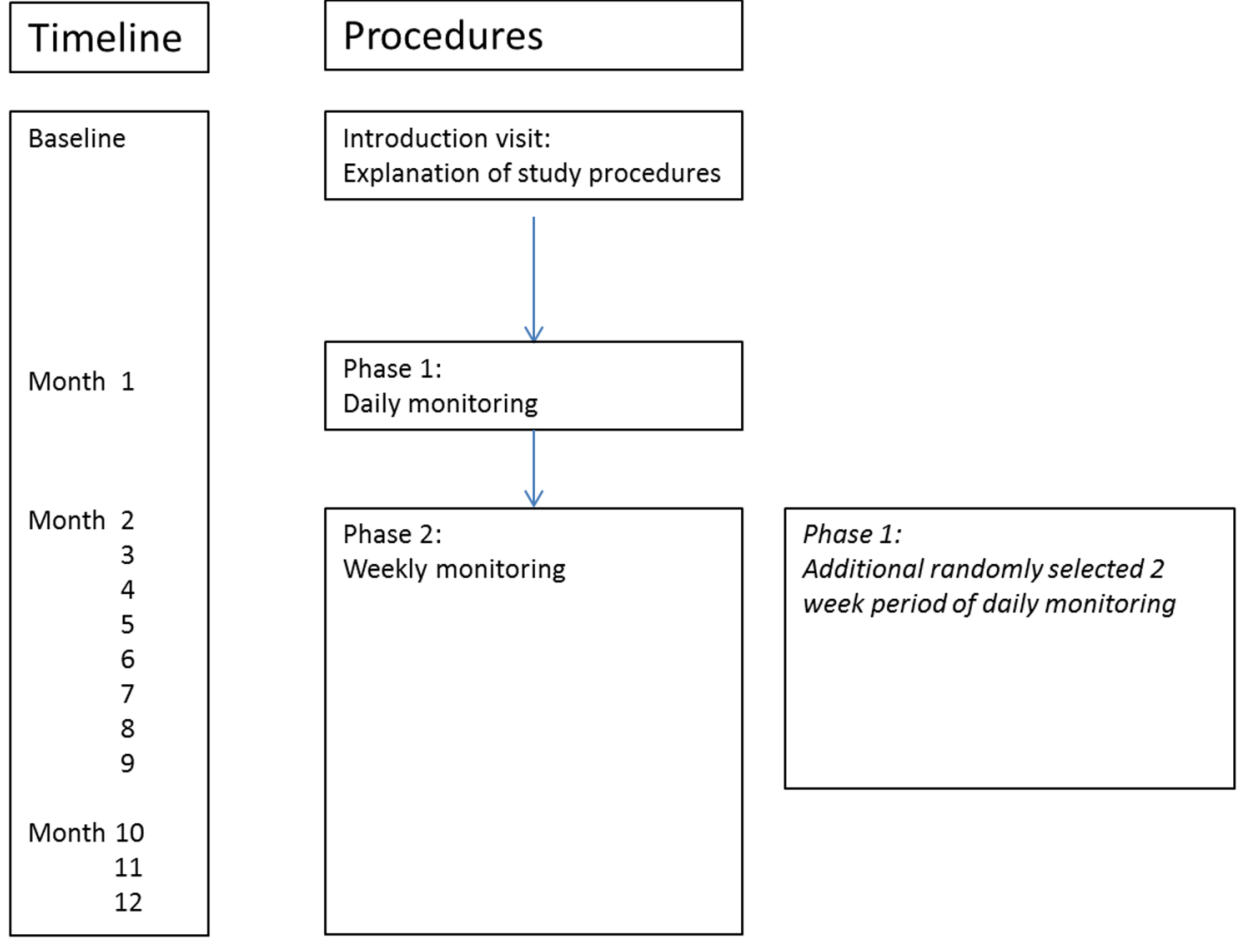

- Introduction visit: all devices and study procedures are explained.

- Phase I: 1-month period of daily monitoring of asthma.

- Phase II: 11-month period of weekly monitoring of asthma. During this phase, a second 2-week period of daily monitoring will be randomly assigned between months 2-9, with the purpose to assess the influence of exposure during different seasons on patient's asthma.

The study enrolment is planned to start in September 2016 and the final patient is planned to finish in March 2018.

\section{Outcomes}

Main study end points will be:

The association of physiological, behavioural and environmental data, alone and in combination, with;

- Phase I: episodes of (un)controlled asthma (as determined by the Asthma Control Diary ${ }^{15}$ ).

- Phase II: occurrence of moderate and severe asthma exacerbations (as defined by the European Respiratory Society and American Thoracic Society (ERS/ATS) Joint Task Force ${ }^{16}$ ).

Secondary study end points

- User acceptance of mHealth and home-monitoring systems, as determined by user adherence to measurements and the After-Scenario Questionnaire (ASQ) feedback. $^{17}$

- The influence of seasonality on the primary end points.

\section{Measurements}

Measurements will differ between phase I and phase II of the observational study and are summarised in table 1 .

\section{Questionnaires}

Asthma control will be measured using the Asthma Control Diary (ACD) ${ }^{15}$ for daily measurements or the Asthma Control Questionnaire (ACQ) ${ }^{18}$ at screening and for weekly measurements. Medication usage will be measured using a custom-designed questionnaire. The mini Asthma Quality of Life Questionnaire (m-AQLQ ${ }^{19}$ ) will be used to determine the quality of life. Dietary information will be recorded using the GA ${ }^{2} L E N$ Food Frequency Questionnaire $\left(\mathrm{FFQ}^{20}\right)$. Anxiety and depression will be measured using the Hospital Anxiety and Depression Scale $\left(\mathrm{HADS}^{21}\right)$, whereas health behaviour and insight will be determined using the health Education Impact Questionnaire $\left(\mathrm{hEIQ}^{22}\right)$. Upper airway symptoms will be assessed using the Sino-Nasal Outcome Test (SNOT-22 $2^{23}$ ) and the usability of all the devices using the $\mathrm{ASQ}^{17}$. For a detailed description of all questionnaires, see online supplement.

The occurrence of exacerbations will be assessed using a daily and weekly custom questionnaire, for phase I and phase II, respectively. The following definitions of exacerbations will be used: ${ }^{16}$

- Severe asthma exacerbations: the occurrence of at least one of the following:

- Use of systemic corticosteroids (tablets, suspension or injection), or an increase from a stable maintenance dose, for at least 3 days. (For consistency, courses of corticosteroids separated by 1 week or more should be registered as separate severe exacerbations.)

- A hospitalisation or emergency room (ER) visit because of asthma, requiring systemic corticosteroids. 
Table 1 Study measurements

\begin{tabular}{|c|c|c|c|c|}
\hline & Introduction visit & Phase I & Phase II & 2 Week-daily monitoring phase \\
\hline \multicolumn{5}{|l|}{ Demographics } \\
\hline Patient characteristics & Once & - & - & - \\
\hline \multicolumn{5}{|l|}{ Questionnaires } \\
\hline ACD & - & Daily & - & Daily \\
\hline $\mathrm{ACQ}$ & Once & - & Weekly & - \\
\hline Medication diary & - & Daily & Weekly & Daily \\
\hline Exacerbation question & - & Daily & Weekly & - \\
\hline m-AQLQ & Once & End of phase I & Monthly & - \\
\hline $\mathrm{GA}^{2} \mathrm{LEN} F F Q$ & Once & - & End of phase II & - \\
\hline HADS & Once & - & - & - \\
\hline hEIQ & Once & - & - & - \\
\hline SNOT-22 & Once & End of phase I & Monthly & - \\
\hline ASQ & - & End of phase I & Biannually & - \\
\hline \multicolumn{5}{|c|}{ Clinical tests and home-monitoring/mHealth systems } \\
\hline Allergy test & Once $^{*}$ & - & - & - \\
\hline Reversibility test & Once* & - & - & - \\
\hline Spirometry & Once & Two times per day & Weekly & Two times per day \\
\hline FeNO & Once & Two times per day & Weekly & Two times per day \\
\hline Breath temperature & Once & Two times per day & Weekly & Two times per day \\
\hline HR and activity level & - & Continuous & Continuous & Continuous \\
\hline Respiratory rate & - & Continuous & Continuous & Continuous \\
\hline Inhaler usage & - & Continuous & Continuous & Continuous \\
\hline Environmental data & - & Continuous & Continuous & Continuous \\
\hline \multicolumn{5}{|c|}{$\begin{array}{l}{ }^{*} \text { Performed if there is no previous test in medical notes. Atopy will be assessed by skin prick tests, }{ }^{24} \text { or measuring levels of specific IgE in } \\
\text { serum. forced expiratory volume in the first second before and after bronchodilation will be assessed using standardised spirometry according } \\
\text { to the ERS criteria. } \\
\text { ACD, Asthma Control Diary; ACQ, Asthma Control Questionnaire; ASQ, After-Scenario Questionnaire; FeNO, fraction of exhaled nitric oxide; } \\
\text { GA LEN FFQ, Global Allergy and Asthma European Network Food frequency Questionnaire; HADS, Hospital Anxiety and Depression } \\
\text { Scale; hEIQ, Health Education and Impact Questionnaire; m-AQLQ, mini Asthma Quality of Life Questionnaire; SNOT-22, Sino-Nasal } \\
\text { Outcome Test 22. }\end{array}$} \\
\hline
\end{tabular}

- Moderate asthma exacerbations: the occurrence of at least one or more of the following:

- deterioration in symptoms,

- deterioration in lung function and

- increased rescue bronchodilator use.

These features should last for 2 days or more, but not be severe enough to warrant systemic corticosteroid use and/or hospitalisation. ER visits for asthma (eg, for routine sick care), not requiring systemic corticosteroids, will be also classified as moderate exacerbations.

\section{Clinical tests and home-monitoring/mHealth systems}

The following devices will be used during the study: Piko-1 device, NIOX VERO, X-Halo, Spire, Fitbit HR Charge and the Smartinhaler.

Participants will use the PIKO-1 device (nSpire Health, Piko-1 device; available at http://www.nspirehealth.com) to perform spirometry measurements.

Fraction of exhaled nitric oxide $(\mathrm{FeNO})$ will be measured at home, in the morning and evening, in a $10 \mathrm{~s}$ exhalation manoeuvre using the NIOX-VERO (Aerocrine, NIOX VERO device; available at http:// www.niox.com/en/). The device is provided to the participants for the duration of the study, and it guides participants through the manoeuvre audiovisually and gives an alert when it is performed incorrectly.
Exhaled breath temperature (EBT) will be performed at home by participants using the X-halo device (Delmedica, X-Halo device; available at http://www. x-halo.com/index.php). This device also includes detailed audiovisual feedback and alerts when used incorrectly.

The respiratory rate (RR) will be measured using the Spiro-device (Spire 2015, The Spire device; available at http://www.spire.io). This device is worn on the belt or bra and requires no particular action other than wearing.

Physical activity and heart rate monitoring will be assessed using the Fitbit HR Charge (Fitbit, Fitbit charge HR; available at http://www.fitbit.com). This device is worn on the wrist and automatically collects data.

Medication adherence will be monitored using the Smartinhaler device (Adherium (NZ) Limited 20132015, Smartinhaler device; available at http://www. smartinhaler.com). The device records information on compliance with regular treatment and need of reliever medications.

Pollen concentrations are measured in the air at the Leiden University Medical Center. Additionally, it provides a daily, 5-day pollen forecast, based on pollen concentrations in previous years and weather forecast. ${ }^{26} 27$ In the UK, the Meteorological Office (Met Office) 
manages a pollen count monitoring network, using information from their network, weather data and expertise from organisations such as the National Pollen and Aerobiological Unit and Pollen UK. ${ }^{28} 29$ Daily pollen levels will be recorded at participants' home and work postcodes.

The air quality will also be monitored. Measurements will be assessed in a similar manner in the UK and the Netherlands. In the UK, the Department for Environment, Food and Rural Affairs (DEFRA) provides in-depth information on air quality and air pollution. ${ }^{28}$ In the Netherlands, the air quality monitoring network mainly hosted by the Netherlands National Institute for Public Health and the Environment (RIVM) provides information on measured air quality at many points throughout the Netherlands. ${ }^{27}$ Based on postal codes of participant's home address and work address, the appropriate measurement station will be selected. The following components will be monitored:

- PM10: PM10 is a collective term for suspended particles that can be inhaled, with a maximum diameter of $0.01 \mathrm{~mm}$. The concentration of fine particulates is higher around the morning and evening rush hour. Weather and traffic emissions have a great impact on the concentration.

- PM2.5: PM2.5 is a collective term for suspended particles that can be inhaled, with a maximum diameter of $0.0025 \mathrm{~mm}$. Similarly to PM10, the concentration of fine particulates is higher around the morning and evening rush hour and dependent on the weather and traffic emissions. As PM2.5 particles are even smaller than PM10 particles, they are able to penetrate even deeper into the lungs and are therefore more harmful from a health perspective.

- Carbon monoxide: it is formed when a substance is burned at low oxygen levels. Traffic is a main source of carbon monoxide in the air.

- $\mathrm{O}_{3}$ : the concentration of ozone $\left(\mathrm{O}_{3}\right)$ is an indicator of the level of smog. The concentration of $\mathrm{O}_{3}$ is dependent on sun exposure and therefore highest during good summer weather.

- $\mathrm{NO}_{2}$ : the concentration of nitrogen dioxide is highly related to traffic exposure.

Weather conditions and forecast are also collected, including temperature, humidity, wind speed and forecasts. They will be measured at post code level.

\section{Statistical analysis}

Statistical methods

Collected data will be analysed with several tools such as cluster, ${ }^{30}$ spectral and factor analyses, ${ }^{31}$ in order to reveal which parameters allow for the prediction of periods of uncontrolled asthma. Additionally, we will perform a similar analysis for phase II of the trial, where the dependent variable is the onset of (severe) exacerbations. Analyses will be performed in collaboration with the University of Patras and the Centre for Research and Technology Hellas (CERTH), who have previous experience in the handling of these types of continuous data. ${ }^{32-35}$ In addition, the anonymised data set will be input for a clinical state prediction engine and risk assessment, which will be used in future parts of the myAirCoach project. Furthermore, a spatial-temporal model will be generated using artificial intelligence methods and data related to user activity and physiological classification. Probabilistic techniques, that is, Bayesian network, will be applied on a provided set of parameters to give probabilistic prediction of specific indicators. Different soft computing, probabilistic and data mining techniques will be applied on the sensors' signals/data to provide least error prone analysis and decision support.

\section{Sample size}

This is a single-cohort observational study in which we aim to assess whether a wide variety of parameters, alone, or in combination, will be able to predict the occurrence of either uncontrolled asthma or asthma exacerbations. As such, we were not able to perform an appropriate sample size calculation. However, with 150 patients daily monitoring for $6(4+2)$ weeks, we will obtain $150 * 6 * 7=6300$ daily entries of measurements in this study. In addition to the daily monitoring, with 150 patients monitoring for 52 weeks, we will obtain $150 * 52$ weeks $=7800$ weekly entries of measurements in this study. Furthermore, we also add the total number of daily/hourly/quarterly data that are automatically generated by the wearables, including the wristband and the respiratory rate monitoring device. These amounts of data should allow for a sufficiently confident prediction.

\section{Data collection}

Online questionnaires and home measurement data will be filled-in by the patient using the monitoring and research modules of the self-management support internet application PatientCoach. ${ }^{36}$ A 'to do' list will be available in PatientCoach specifically designed for this research and will provide links to the appropriate questionnaires and data entry forms at the appropriate moment (figure 2A, B). This 'to do' list web page will be preinstalled in an app on an iPod touch 6th generation (2015 Apple, iPod touch 6, available at http:// www.apple.com). Applications for the Spire, Fitbit HR and Smartinhaler devices will be preinstalled on the iPod. Using Bluetooth and Wifi connections, the data stored on these devices will be regularly transmitted to and subsequently safely stored within the PatientCoach system.

\section{Dissemination}

We plan to communicate final results to participants, healthcare professionals, policymakers, the funder, the public and other relevant groups via conferences, publication or other data sharing arrangements. A final study report will also be send to the Medical Ethics Committees within 1 year of finalisation. 
Figure 2 ( $A$ and $B$ ) A view of a participant's iPod. In (A), a general overview of the iPod screen after turning it on and in (B), a screenshot of a 'to do' list within the PatientCoach system. ACQ, Asthma Control Questionnaire; GA ${ }^{2}$ LEN FFQ, Global Allergy and Asthma European Network Food frequency Questionnaire; HADS, Hospital Anxiety and Depression Scale; hEIQ, Health Education and Impact Questionnaire; m-AQLQ, mini Asthma Quality of Life Questionnaire; SNOT-22, Sino-Nasal Outcome Test 22.
A

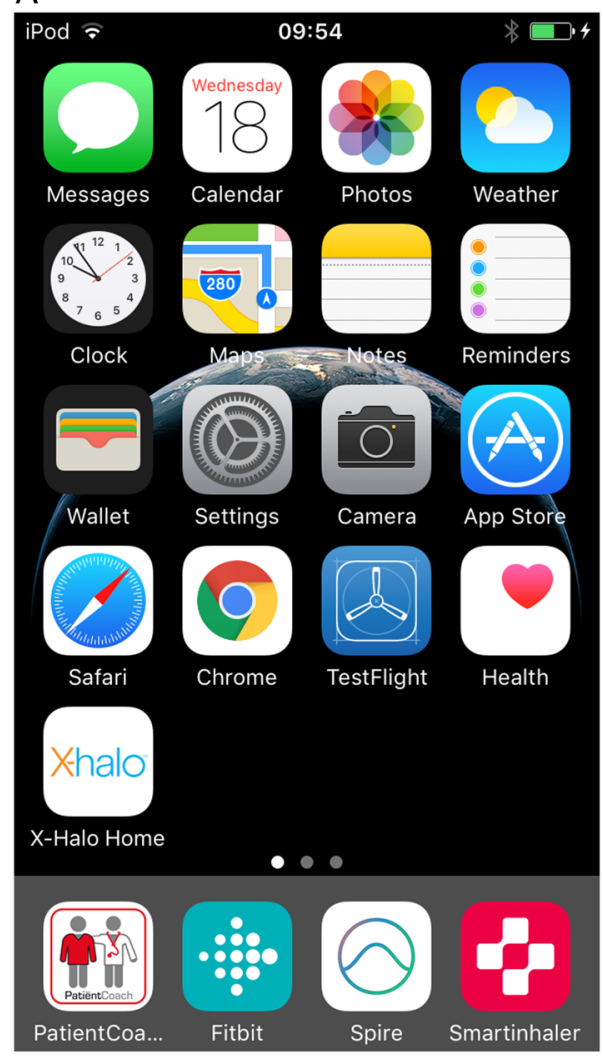

B

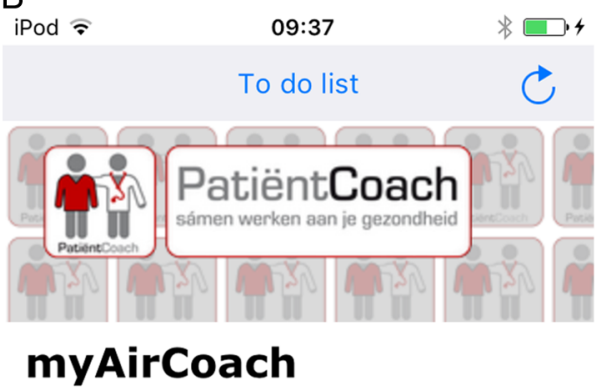

Weekly

Planned: Fri, 13/01/2017

Link

ACQ week

Date

Piko-1 (FEV1)

$\checkmark$ Tue, 17/01/2017

NIOX Vero (FeNO)

$\checkmark$ Tue, $17 / 01 / 2017$

X-halo (EBT)

$\checkmark$ Tue, $17 / 01 / 2017$

$\checkmark$ Tue, 17/01/2017

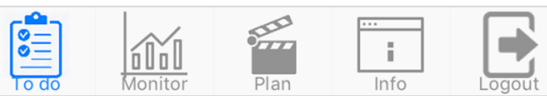

\section{DISCUSSION}

\section{Main expected outcome}

In the present study, we aim to determine the extent to which mHealth, home-monitoring sensors and environmental databases can predict (un)controlled asthma and exacerbations. Initially, we will determine this ability for each individual device. However, more importantly, we plan to combine data in order to increase sensitivity and specificity, allowing us to determine optimal action points at which to intervene in order to prevent loss of control or exacerbations.

\section{Choice of parameters}

For the present study, we needed to make a selection of all currently available sensors and monitoring devices and for some, like spirometry, FeNO and pollen counts, this is based on evidence-based criteria. However, our study aims to be innovative; therefore, a lot of our devices are new in the management of asthma and are selected based on their potential value.

We added a spirometry measurement using Piko, since spirometry is one of the most commonly used measurements in asthma. Also, traditional asthma action plans, aimed at predicting loss of control or asthma exacerbations, already involve regular measurements of peak flow or forced expiratory volume in the first second and have been shown to be beneficial for asthma self-management. ${ }^{37} 38$

FeNO will be assessed since patients with allergic airway inflammation generally have higher than normal levels. By measuring FeNO, we aim to evaluate allergic airway inflammation in patients with underlying asthma. Measuring FeNO during regular control visits to assess current asthma control has been shown to be effective, ${ }^{39-42}$ although there have been some contrasting results. ${ }^{43-45}$ Daily monitoring of FeNO might prove to be of additional value. van der Valk $e t a t^{46}$ analysed daily measurements of FeNO by different types of mathematical techniques in order to look at periods of exacerbations relative to reference periods in the same patient. The analysis showed that there are changes in FeNO before the onset of exacerbations compared to reference periods. These findings support that regular FeNO measurements in the home setting could help to predict changes in asthma control.

Evaluation of EBT has been suggested as a new method to detect and monitor pathological processes in the respiratory system. The putative mechanism of this approach is based on changes in the blood flow in the conducting airways that are characteristic of different disease states, which influence the temperature of the exhaled gases. Thus far, associations between EBT on the one hand and bronchial blood flow, FeNO and sputum cellular content on the other have been demonstrated. ${ }^{47}$

The RR is one of the vital signs and has been an integral part of the assessment of asthmatic patients in an acute setting for decades. ${ }^{2}$ Previous research showed that variability of RR during sleep is different in asthmatics. ${ }^{48}$ Additionally, an increased resting RR during the day might also indicate loss of asthma control. 
Therefore, continuous analysis of RR during the day and while sleeping might prove useful in the prediction of asthma control.

Pulse rate can be easily measured by currently available wristbands. The Fitbit additionally assesses activity level. The added value of monitoring these parameters in asthma has not been established, yet they potentially provide relevant information about the clinical state of asthma including the severity of exacerbations when evaluated in combination with other clinical outcomes. ${ }^{49}$

Environmental factors and stimuli have a major impact on the clinical state of patients with asthma. There is a clear link between the amount of pollen and deterioration of asthma symptoms in allergic asthmatics. ${ }^{50}$ Continuous data on exposure to pollen and associated feedback, especially in established allergies, might aid in preventing loss of control on asthma. ${ }^{27} 51$ Furthermore, other environmental factors, such as air pollution, also contribute to increased morbidity in asthma, and diminished lung function in children raised in a polluted environment. ${ }^{52}{ }^{53}$ Finally, certain weather conditions might also prove to be relevant for predicting asthma control.

\section{Future implications}

This study is part of the European Union Horizon 2020 funded myAirCoach project. The final aim of this project is to develop a holistic mHealth personalised asthma-monitoring system empowering patients to manage their own health by providing user-friendly tools to increase the awareness of their clinical state and effectiveness of medical treatment. To this purpose, a large consortium of leading clinicians in the field of asthma, engineers from technical universities, technical and pharmaceutical companies and representatives of patients' organisations was assembled, creating a unique environment of highly qualified experts, sharing different insights into problems and potential solutions a project such as this poses. In the present study, data from a wide variety of measurements, including sensors, home-monitoring systems and environmental databases, are collected and patients still need to manually report current symptoms and occurrence of exacerbations on questionnaires on their iPod. This requires intensive entry of questionnaires by patients in this phase of the entire myAirCoach project. This is needed to determine the association between symptoms/exacerbations and data from each of these measurements separately and combinations between measurements. However, if we manage to establish associations, manual entry of questionnaires is no longer required. We might use these established associations in our final model to predict asthma control and exacerbations, by real-time analysis of automatically collected continuous measurements from individual patients. We envisage a final system, where people with asthma will only be required to wear certain sensors and they will receive automated, personalised feedback via an app, for instance on their mobile phone. A 'personal mHealth guidance system' will empower patients to customise their treatment towards personalised preset goals and guidelines, either automatically or driven by healthcare professional. In this context, myAirCoach will give to clinicians early indications of increasing symptoms or exacerbations, while making an important contribution in successful selfmanagement of asthma.

Additionally, in another part of the myAirCoach study, we are seeking to obtain end-user (people with asthma and healthcare professionals) opinions on the uses and applications of mHealth, in collaboration with patientfocused groups (asthma UK and The European Federation of Allergy and Airways Diseases Patients' Associations (EFA)), and will take these opinions into account in the design of the final prototype.

Besides the obvious necessity of the current study to ground the final myAirCoach framework with data, these results are also expected to lead to increased confidence in the myAirCoach approach and in online decision support and self-management systems in general. The impact of such a holistic and innovative approach is huge, and the foundations laid here are expected to result in a widespread adoption of sensor-based selfmanagement systems not only in asthma, but also in other respiratory diseases.

\section{Author affiliations}

${ }^{1}$ Department of Quality of Care, Leiden University Medical Center, Leiden, The Netherlands

${ }^{2}$ Department of Medical Decision Making, Leiden University Medical Center, Leiden, The Netherlands

${ }^{3}$ Centre for Respiratory Medicine and Allergy, Institute of Inflammation and Repair, Manchester Academic Health Science and Centre, The University of Manchester University Hospital of South Manchester, NHS Foundation Trust, Manchester, UK

${ }^{4}$ National Heart and Lung Institute (NHLI), Imperial College London, London, UK

Collaborators MyAirCoach study group: N. Chavannes, C. Taube, R. Niven

Contributors PJH is the main author of the study protocol and this manuscript. OSU, KFC, SF and JKS secured the funding of this study. PJH, AS, MB, JBS and SM obtained ethical and privacy approval. PJH and AS drafted the manuscript. MB, JBS, SM, OSU, KFC, SF and JKS critically revised the manuscript.

Funding This study is funded by an EU HORIZON 2020 grant: section 'Self-management of health and disease: citizen engagement and mHealth' (grant number 643607).

Competing interests KFC reports personal fees from Advisory Board membership, grants for research, personal fees from payments for lectures, outside the submitted work. OSU reports grants from AstraZeneca, personal fees from Boehringer Ingelheim, grants and personal fees from Chiesi, personal fees from Aerocrine, grants from GlaxoSmithKline, personal fees from Napp, personal fees from Mundipharma, personal fees from Sandoz, grants from Prosonix, personal fees from Takeda, personal fees from Zentiva, grants from Edmond Pharma, personal fees from Cipla, outside the submitted work. JKS reports grants from GlaxoSmithKline NL, grants from Chiesi NL, outside the submitted work.

Ethics approval Leiden University Medical Center and NHS ethics service.

Provenance and peer review Not commissioned; externally peer reviewed.

Open Access This is an Open Access article distributed in accordance with the Creative Commons Attribution Non Commercial (CC BY-NC 4.0) license, 
which permits others to distribute, remix, adapt, build upon this work noncommercially, and license their derivative works on different terms, provided the original work is properly cited and the use is non-commercial. See: http:// creativecommons.org/licenses/by-nc/4.0/

\section{REFERENCES}

1. Masoli M, Fabian D, Holt S, et al. The global burden of asthma: executive summary of the GINA Dissemination Committee report. Allergy 2004;59:469-78.

2. The Global Strategy for Asthma Management and Prevention, Global Initiative for Asthma (GINA) 2015. http://www.ginasthma.org/

3. Wenzel S, Denver D, Fahy J, et al. Proceedings of the ATS workshop on refractory asthma: current understanding, recommendations, and unanswered questions, American Thoracic Society. Am J Respir Crit Care Med 2000;162:2341-51.

4. Peters SP, Ferguson G, Deniz $Y$, et al. Uncontrolled asthma: a review of the prevalence, disease burden and options for treatment. Respir Med 2006;100:1139-51.

5. Dean BB, Calimlim BM, Kindermann SL, et al. The impact of uncontrolled asthma on absenteeism and health-related quality of life. J Asthma 2009;46:861-6.

6. Gibson PG, Powell H, Coughlan J, et al. Self-management education and regular practitioner review for adults with asthma. Cochrane Database Syst Rev 2003;1:CD001117.

7. Haughney J, Barnes G, Partridge M, et al. The Living \& Breathing Study: a study of patients' views of asthma and its treatment. Prim Care Respir J 2004;13:28-35.

8. Kaya Z, Erkan F, Ozkan M, et al. Self-management plans for asthma control and predictors of patient compliance. J Asthma 2009;46:270-275.

9. McCurdie T, Taneva S, Casselman M, et al. mHealth consumer apps: the case for user-centered design. Biomed Instrum Technol 2012;(Suppl 2):49-56.

10. van der Meer V, Bakker MJ, van den Hout WB, et al. Internet-based self-management plus education compared with usual care in asthma: a randomized trial. Ann Intern Med 2009;151:110-20.

11. de Jongh T, Gurol-Urganci I, Vodopivec-Jamsek V, et al. Mobile phone messaging for facilitating self-management of long-term illnesses. Cochrane Database Syst Rev 2012;12:CD007459.

12. Reddel HK, Jenkins CR, Partridge MR. Self-management support and other alternatives to reduce the burden of asthma and chronic obstructive pulmonary disease. Int $J$ Tuberc Lung Dis 2014:18:1396-406.

13. van Gaalen JL, Hashimoto S, Sont JK. Telemanagement in asthma: an innovative and effective approach. Curr Opin Allergy Clin Immunol 2012;12:235-40.

14. Huckvale K, Car M, Morrison C, et al. Apps for asthma self-management: a systematic assessment of content and tools. BMC Med 2012;10:144.

15. Juniper EF, O'Byrne PM, Ferrie PJ, et al. Measuring asthma control. Clinic questionnaire or daily diary? Am J Respir Crit Care Med 2000;162:1330-4.

16. Reddel HK, Taylor DR, Bateman ED, et al. An official American Thoracic Society/European Respiratory Society statement: asthma control and exacerbations: standardizing endpoints for clinical asthma trials and clinical practice. Am J Respir Crit Care Med 2009;180:59-99.

17. Lewis JR. Psychometric evaluation of an after-scenario questionnaire for computer usability studies: the ASQ. SIGCHI Bull 1991:23:78-81.

18. Juniper EF, O'Byrne PM, Guyatt GH, et al. Development and validation of a questionnaire to measure asthma control. Eur Respir J 1999;14:902-7

19. Juniper EF, Guyatt GH, Cox FM, et al. Development and validation of the Mini Asthma Quality of Life Questionnaire. Eur Respir J 1999;14:32-8

20. Garcia-Larsen V, Luczynska M, Kowalski ML, et al. Use of a common food frequency questionnaire (FFQ) to assess dietary patterns and their relation to allergy and asthma in Europe: pilot study of the GA2LEN FFQ. Eur J Clin Nutr 2011;65:750-6.

21. Snaith RP. The Hospital Anxiety And Depression Scale. Health Qual Life Outcomes 2003;1:29.

22. Osborne RH, Elsworth GR, Whitfield K. The Health Education Impact Questionnaire (hEIQ): an outcomes and evaluation measure for patient education and self-management interventions for people with chronic conditions. Patient Educ Couns 2007;66:192-201.

23. Hopkins C, Gillett S, Slack R, et al. Psychometric validity of the 22-item Sinonasal Outcome Test. Clin Otolaryngol 2009;34:447-54

24. Bousquet $\mathrm{J}$, Heinzerling $\mathrm{L}$, Bachert $\mathrm{C}$, et al. Practical guide to skin prick tests in allergy to aeroallergens. 2012;67:18-24.
25. Miller MR, Hankinson JL, Brusasco V, et al. Standardisation of spirometry. Eur Respir J 2005;26:319-38.

26. de Weger LA, Beerthuizen T, Hiemstra PS, et al. Development and validation of a 5-day-ahead hay fever forecast for patients with grass-pollen-induced allergic rhinitis. Int J Biometeorol 2014;58:1047-55.

27. Luchtmeetnet. http://www.luchtmeetnet.nl (accessed 2015).

28. Department for Environment, Food and Rural Affairs (DEFRA) is linked to the UK-AIR (Air Information Resource). http://uk-air.defra. gov.uk/ (accessed 2015)

29. National Pollen and Aerobiological Unit. http://www.worc.ac.uk/ discover/national-pollen-and-aerobiology-research-unit.html (accessed 2015).

30. Haldar P, Pavord ID, Shaw DE, et al. Cluster analysis and clinical asthma phenotypes. Am J Respir Crit Care Med 2008;178:218-24.

31. Juniper EF, Wisniewski ME, Cox FM, et al. Relationship between quality of life and clinical status in asthma: a factor analysis. Eur Respir J 2004;23:287-91.

32. Giakoumis D, Tzovaras D, Hassapis G. Subject-dependent biosigna features for increased accuracy in psychological stress detection. Int J Hum-Comput Stud 2013;71:425-39.

33. Giakoumis D, Drosou A, Cipresso P, et al. Using activity-related behavioural features towards more effective automatic stress detection. PLOS ONE 2012;7:e43571.

34. SoltaniHeris T, Langarizadeh M, Mahmoodvand Z, et al. Intelligent diagnosis of asthma using machine learning algorithms. Int Res J Appl Basic Sci 2013;4:4041-6.

35. Finkelstein J, Wood J. Predicting asthma exacerbations using artificial intelligence. Stud Health Technol Inform 2013;190:56-8.

36. Patient Coach platform. http://www.PatientCoach.nl/ (accessed 2015).

37. Honkoop PJ, Taylor DR, Smith AD, et al. Early detection of asthma exacerbations by using action points in self-management plans. Eur Respir J 2013;41:53-9.

38. Gibson PG, Powell H. Written action plans for asthma: an evidence-based review of the key components. Thorax 2004;59:94-9.

39. Smith AD, Cowan JO, Brassett KP, et al. Use of exhaled nitric oxide measurements to guide treatment in chronic asthma. $N$ Engl J Med 2005;352:2163-73.

40. Powell H, Murphy VE, Taylor DR, et al. Management of asthma in pregnancy guided by measurement of fraction of exhaled nitric oxide: a double-blind, randomised controlled trial. Lancet 2011;378:983-90.

41. Honkoop PJ, Loymans RJ, Termeer EH, et al. Symptom- and fraction of exhaled nitric oxide-driven strategies for asthma control: a cluster-randomized trial in primary care. JACI 2015;135:682-825.

42. Pavord ID, Shaw D. The use of exhaled nitric oxide in the management of asthma. J Asthma 2008;45:523-31.

43. Szefler SJ, Mitchell H, Sorkness CA, et al. Management of asthma based on exhaled nitric oxide in addition to guideline based treatment for inner-city adolescents and young adults: a randomized controlled trial. Lancet 2008;372:1065-72.

44. De Jongste JC, Carraro S, Hop WC, et al. Daily telemonitoring of exhaled nitric oxide and symptoms in the treatment of childhood asthma. Am J Respir Crit Care Med 2009;179:93-7.

45. Shaw DE, Berry MA, Thomas $M$, et al. The use of exhaled nitric oxide to guide asthma management: a randomized controlled trial. Am J Respir Crit Care Med 2007;176:231-7.

46. van der Valk RJ, Baraldi E, Stern G, et al. Daily exhaled nitric oxide measurements and asthma exacerbations in children. Allergy 2012;67:265-71.

47. Popov TA, Kralimarkova TZ, Dimitrov VD. Measurement of exhaled breath temperature in science and clinical practice. Breathe 2012;8:187-92.

48. Campaa LM, Owens RL, Butler JP, et al. Variability of respiratory mechanics during sleep in overweight and obese subjects with and without asthma. Respir Physiol Neurobiol 2013;186:290-5.

49. Lufti MF. Autonomic modulations in patients with bronchial asthma based on short-term heart rate variability. Lung India 2012;29:254-8.

50. Djukanović R, Feather I, Gratziou C, et al. Effect of natural allergen exposure during the grass pollen season on airways inflammatory cells and asthma symptoms. Thorax 1996;51:575-81.

51. Pollen UK to produce forecasts that help support allergy and hay fever sufferers through the most difficult time of the year. http://www. metoffice.gov.uk/health/public/pollen-forecast (accessed 2015).

52. Gauderman WJ, Avol E, Gilliland F, et al. The effect of air pollution on lung development from 10 to 18 years of age. $N$ Engl $J$ Med 2004;351:1057-67.

53. Wong GW, Lai CK. Outdoor air pollution and asthma. Curr Opin Pulm Med 2004;10:62-6. 